\title{
Mixed type iterations for multivalued nonexpansive mappings in hyperbolic spaces
}

\author{
Xian-Cai Lei ${ }^{1}$, Hua Li ${ }^{2}$ and Lan $\mathrm{Di}^{3^{*}}$
}

\section{"Correspondence:}

dilan126@163.com

${ }^{3}$ School of Digital Media, Jiangnan

University, Wuxi, Jiangsu 214122,

China

Full list of author information is

available at the end of the article

\begin{abstract}
The purpose of this paper is to extend the iteration scheme of multivalued nonexpansive mappings from a Banach space to a hyperbolic space by proving $\Delta$-convergence theorems for two multivalued nonexpansive mappings in terms of mixed type iteration processes to approximate a common fixed point of two multivalued nonexpansive mappings in hyperbolic spaces. The results presented in this paper are new and can be regarded as an extension of corresponding results from Banach spaces to hyperbolic spaces in the literature.
\end{abstract}

MSC: $47 \mathrm{H} 10 ; 54 \mathrm{H} 25$

Keywords: mixed type iteration; multivalued nonexpansive mapping; common fixed point; Banach space; hyperbolic space

\section{Introduction and preliminaries}

The study of fixed points for multivalued contractions and nonexpansive mappings using the Hausdorff metric was initiated by Markin [1] (see also [2]). Later, various iterative processes have been used to approximate the fixed points of multivalued nonexpansive mappings in Banach space, for example, the authors of [1-17] and $[18,19]$ have made extensive research in this direction, which has led to many new results in the study of fixed point theory with applications in control theory, convex optimization, differential inclusion, economics, and related topics (see [3] and references cited therein for details).

This is so because of the fact that in general almost all problems in various disciplines of science are nonlinear in nature, and most results of fixed point theory are proposed under the framework of normed linear spaces or Banach spaces as the property of nonlinear mappings may depend on the linear structure of the underlying spaces. Thus it is necessary to study fixed point theory for nonlinear mappings under the space which does not have a linear structure but is embedded with a kind of 'convex structures'. The class of hyperbolic spaces, being nonlinear in nature, is a general abstract theoretic setting with rich geometrical structures for metric fixed point theory. Thus the study of fixed point theory for hyperbolic spaces has been largely motivated and dominated by questions from nonlinear problems in practice, such as problems of geometric group theory, and others. However, so far, we have seen not many results for the approximation iteration of multivalued nonexpansive mappings in terms of Hausdorff metrics for fixed points in the existing literature. The purpose of this paper is to extend the iteration scheme of multivalued nonexpansive mappings from a Banach space to a hyperbolic space by proving $\Delta$-convergence

(2014 Lei et al: licensee Springer. This is an Open Access article distributed under the terms of the Creative Commons Attribution License (http://creativecommons.org/licenses/by/2.0), which permits unrestricted use, distribution, and reproduction in any medium, provided the original work is properly cited. 
theorems for two multivalued nonexpansive mappings in terms of mixed type iteration processes to approximate a common fixed point of two multivalued nonexpansive mappings in hyperbolic spaces. The results presented in this paper are new and can be regarded as an extension of corresponding results from Banach spaces to hyperbolic spaces in the existing literature given by the authors of $[6-9,11-13,15,16,18-21]$.

In order to define the concept of multivalued nonexpansive mapping in the general setup of Banach spaces, we first collect some basic concepts.

Let $E$ be a real Banach space. A subset $K$ is called proximinal if for each $x \in E$, there exists an element $k \in K$ such that

$$
d(x, k)=\inf \{\|x-y\|: y \in K\}=d(x, K) .
$$

It is well known that weakly compact convex subsets of a Banach space and closed convex subsets of a uniformly convex Banach space are proximinal. We shall denote the family of nonempty bounded proximinal subsets of $K$ by $P(K)$. By following the notation used by Markin in [1], let $C B(K)$ be the class of all nonempty bounded and closed subsets of $K$. Let $H$ be a Hausdorff metric induced by the metric $d$ of $E$, that is,

$$
H(A, B)=\max \left\{\sup _{x \in A} d(x, B), \sup _{y \in B} d(y, A)\right\},
$$

for every $A, B \in C B(E)$. A multivalued mapping $T: K \rightarrow P(K)$ is said to be a contraction if there exists a constant $k \in[0,1)$ such that for any $x, y \in K$,

$$
H(T x, T y) \leq k\|x-y\|
$$

Definition 1.1 [15] A multivalued mapping $T: K \rightarrow P(K)$ is said to be nonexpansive, if

$$
H(T x, T y) \leq\|x-y\|, \quad \forall x, y \in K .
$$

Lemma 1.2 [12] Let $T: K \rightarrow P(K)$ be a multivalued mapping and $P_{T}(x)=\{y \in T x: \| x-$ $y \|=d(x, T x)\}$. Then the following are equivalent.

(1) $x \in F(T)$.

(2) $P_{T}(x)=\{x\}$.

(3) $x \in F\left(P_{T}\right)$.

Moreover, $F(T)=F\left(P_{T}\right)$.

Throughout this paper, we work in the setting of hyperbolic spaces introduced by Kohlenbach [22], defined below, which is more restrictive than the hyperbolic type introduced in [23] and more general than the concept of hyperbolic space in [24].

We also recall that a hyperbolic space is a metric space $(X, d)$ together with a mapping $W: X^{2} \times[0,1] \rightarrow X$ satisfying

(i) $d(u, W(x, y, \alpha)) \leq \alpha d(u, x)+(1-\alpha) d(u, y)$;

(ii) $d(W(x, y, \alpha), W(x, y, \beta))=|\alpha-\beta| d(x, y)$;

(iii) $W(x, y, \alpha)=W(y, x,(1-\alpha))$;

(iv) $d(W(x, z, \alpha), W(y, w, \alpha)) \leq(1-\alpha) d(x, y)+\alpha d(z, w)$;

for all $x, y, z, w \in X$ and $\alpha, \beta \in[0,1]$. 
A nonempty subset $K$ of a hyperbolic space $X$ is convex if $W(x, y, \alpha) \in K$ for all $x, y \in K$ and $\alpha \in[0,1]$. The class of hyperbolic spaces contains normed spaces and convex subsets thereof, the Hilbert ball equipped with the hyperbolic metric [20], Hadamard manifolds as well as CAT(0) spaces in the sense of Gromov (see [25]).

A hyperbolic space is uniformly convex [26] if for any $r>0$ and $\epsilon \in(0,2]$ there exists a $\delta \in(0,1]$ such that for all $u, x, y \in X$, we have

$$
d\left(W\left(x, y, \frac{1}{2}\right), u\right) \leq(1-\delta) r,
$$

provided $d(x, u) \leq r, d(y, u) \leq r$ and $d(x, y) \geq \epsilon r$.

A map $\eta:(0, \infty) \times(0,2] \rightarrow(0,1]$ which provides such a $\delta=\eta(r, \epsilon)$ for given $r>0$ and $\epsilon \epsilon$ $(0,2]$ is known as a modulus of uniform convexity of $X$. We call $\eta$ monotone if it decreases with $r$ (for a fixed $\epsilon$ ), i.e., $\forall \epsilon>0, \forall r_{2} \geq r_{1}>0\left(\eta\left(r_{2}, \epsilon\right) \leq \eta\left(r_{1}, \epsilon\right)\right)$.

In the sequel, let $(X, d)$ be a metric space and let $K$ be a nonempty subset of $X$. We shall denote the fixed point set of a mapping $T$ by $F(T)=\{x \in K: T x=x\}$.

We also recall that a single-valued mapping $T: K \rightarrow K$ is said to be nonexpansive, if

$$
d(T x, T y) \leq d(x, y), \quad \forall x, y \in K
$$

In order to establish our new results for thee iteration scheme of multivalued nonexpansive mappings under the framework of hyperbolic spaces, we first recall some facts from the existing literature.

Lemma 1.3 [27] Let $(X, d, W)$ be a complete uniformly convex hyperbolic space with monotone modulus of uniform convexity. Then every bounded sequence $\left\{x_{n}\right\}$ in $X$ has a unique asymptotic center with respect to any nonempty closed convex subset $K$ of $X$.

Recall that a sequence $\left\{x_{n}\right\}$ in $X$ is said to $\Delta$-converge to $x \in X$ if $x$ is the unique asymptotic center of $\left\{u_{n}\right\}$ for every subsequence $\left\{u_{n}\right\}$ of $\left\{x_{n}\right\}$. In this case, we write $\Delta-\lim _{n \rightarrow \infty} x_{n}=$ $x$ and call $x$ the $\Delta$-limit of $\left\{x_{n}\right\}$.

A mapping $T: K \rightarrow K$ is semi-compact if every bounded sequence $\left\{x_{n}\right\} \subset K$ satisfying $d\left(x_{n}, T x_{n}\right) \rightarrow 0$, has a convergent subsequence.

Lemma 1.4 [28] Let $\left\{a_{n}\right\},\left\{b_{n}\right\}$, and $\left\{\delta_{n}\right\}$ be sequences of nonnegative real numbers satisfying

$$
a_{n+1} \leq\left(1+\delta_{n}\right) a_{n}+b_{n}, \quad \forall n \geq 1
$$

if $\sum_{n=1}^{\infty} \delta_{n}<\infty$ and $\sum_{n=1}^{\infty} b_{n}<\infty$, then the limit $\lim _{n \rightarrow \infty} a_{n}$ exists. If there exists a subsequence $\left\{a_{n_{i}}\right\} \subset\left\{a_{n}\right\}$ such that $a_{n_{i}} \rightarrow 0$, then $\lim _{n \rightarrow \infty} a_{n}=0$.

Lemma 1.5 [29] Let $(X, d, W)$ be a uniformly convex hyperbolic space with monotone modulus of uniform convexity $\eta$. Let $x \in X$ and $\left\{\alpha_{n}\right\}$ be a sequence in $[a, b]$ for some $a, b \in(0,1)$. If $\left\{x_{n}\right\}$ and $\left\{y_{n}\right\}$ are sequences in $X$ such that

$$
\limsup _{n \rightarrow \infty} d\left(x_{n}, x\right) \leq c, \quad \limsup _{n \rightarrow \infty} d\left(y_{n}, x\right) \leq c, \quad \lim _{n \rightarrow \infty} d\left(W\left(x_{n}, y_{n}, \alpha_{n}\right), x\right)=c,
$$

for some $c \geq 0$. Then $\lim _{n \rightarrow \infty} d\left(x_{n}, y_{n}\right)=0$. 
Lemma 1.6 [29] Let K be a nonempty closed convex subset of uniformly convex hyperbolic space and $\left\{x_{n}\right\}$ a bounded sequence in $K$ such that $A\left(\left\{x_{n}\right\}\right)=\{y\}$ and $r\left(\left\{x_{n}\right\}\right)=\zeta$. If $\left\{y_{m}\right\}$ is another sequence in $K$ such that $\lim _{m \rightarrow \infty} r\left(y_{m},\left\{x_{n}\right\}\right)=\zeta$, then $\lim _{m \rightarrow \infty} y_{m}=y$.

\section{Main results}

Now we have the following key result in this paper.

Theorem 2.1 Let $K$ be a nonempty closed convex subset of a complete uniformly convex hyperbolic space $X$ with monotone modulus of uniform convexity $\eta$. Let $T_{i}: K \rightarrow P(K)$, $i=1,2$ be a multivalued mapping and $T_{T_{i}}$ be a nonexpansive mapping, let $S_{i}: K \rightarrow P(K)$, $i=1,2$ be a multivalued mapping and $S_{S_{i}}$ be a nonexpansive mapping. Assume that $\mathcal{F}:=$ $\bigcap_{i=1}^{2} F\left(T_{T_{i}}\right) \cap F\left(S_{S_{i}}\right) \neq \emptyset$, and for arbitrarily chosen $x_{1} \in K,\left\{x_{n}\right\}$ is defined as follows:

$$
x_{n+1}=W\left(S_{S_{1}} x_{n}, T_{T_{1}} u_{n}, \alpha_{n}\right), \quad y_{n}=W\left(S_{S_{2}} x_{n}, T_{T_{2}} v_{n}, \beta_{n}\right), \quad \forall n \geq 1,
$$

where $v_{n} \in S_{S_{2}} x_{n}, u_{n} \in S_{S_{1}} y_{n}, d\left(v_{n}, u_{n}\right) \leq H\left(S_{S_{2}} x_{n}, S_{S_{1}} y_{n}\right)+\tau_{n},\left\{\tau_{n}\right\},\left\{\alpha_{n}\right\}$, and $\left\{\beta_{n}\right\}$ satisfy the following conditions:

(1) $\lim _{n \rightarrow \infty} \tau_{n}=0, \sum_{n=1}^{\infty} \tau_{n}<\infty$.

(2) There exist constants $a, b \in(0,1)$ with $0<b(1-a) \leq \frac{1}{2}$ such that $\left\{\alpha_{n}\right\} \subset[a, b]$ and $\left\{\beta_{n}\right\} \subset[a, b]$.

(3) $\left\|x_{n}-p\right\|=d\left(x_{n}, p\right),\left\|y_{n}-p\right\|=d\left(y_{n}, p\right)$.

(4) $d\left(x, T_{T_{i}} y\right) \leq d\left(S_{S_{i}} x, T_{T_{i}} y\right)$, for all $x, y \in K$ and $i=1,2$.

Then the sequence $\left\{x_{n}\right\}$ defined by (2.1) $\Delta$-converges to a common fixed point of $\mathcal{F}:=$ $\bigcap_{i=1}^{2} F\left(T_{T_{i}}\right) \cap F\left(S_{S_{i}}\right)$.

Proof The proof of Theorem 2.1 is divided into three steps:

Step 1. First we prove that $\lim _{n \rightarrow \infty} d\left(x_{n}, p\right)$ exists for each $p \in \mathcal{F}$. For any given $p \in \mathcal{F}$, since $T_{T_{i}}, S_{S_{i}}, i=1,2$, is a multivalued nonexpansive mapping, by condition (2) and (2.1), we have

$$
\begin{aligned}
d\left(x_{n+1}, p\right) & =d\left(W\left(S_{S_{1}} x_{n}, T_{T_{1}} u_{n}, \alpha_{n}\right), p\right) \\
& \leq\left(1-\alpha_{n}\right) d\left(S_{S_{1}} x_{n}, p\right)+\alpha_{n} d\left(T_{T_{1}} u_{n}, p\right) \\
& =\left(1-\alpha_{n}\right) d\left(S_{S_{1}} x_{n}, S_{S_{1}} p\right)+\alpha_{n} d\left(T_{T_{1}} u_{n}, T_{T_{1}} p\right) \\
& \leq\left(1-\alpha_{n}\right) d\left(x_{n}, p\right)+\alpha_{n} d\left(u_{n}, p\right) \\
& \leq\left(1-\alpha_{n}\right) d\left(x_{n}, p\right)+\alpha_{n} H\left(S_{S_{1}} y_{n}, S_{S_{1}} p\right)+\alpha_{n} \tau_{n} \\
& \leq\left(1-\alpha_{n}\right) d\left(x_{n}, p\right)+\alpha_{n}\left\|y_{n}-p\right\|+\alpha_{n} \tau_{n} \\
& =\left(1-\alpha_{n}\right) d\left(x_{n}, p\right)+\alpha_{n} d\left(y_{n}, p\right)+\alpha_{n} \tau_{n},
\end{aligned}
$$

where

$$
\begin{aligned}
d\left(y_{n}, p\right) & =d\left(W\left(S_{S_{2}} x_{n}, T_{T_{2}} v_{n}, \beta_{n}\right), p\right) \\
& \leq\left(1-\beta_{n}\right) d\left(S_{S_{2}} x_{n}, p\right)+\beta_{n} d\left(T_{T_{2}} v_{n}, p\right) \\
& =\left(1-\beta_{n}\right) d\left(S_{S_{2}} x_{n}, S_{S_{2}} p\right)+\beta_{n} d\left(T_{T_{2}} v_{n}, T_{T_{2}} p\right) \\
& \leq\left(1-\beta_{n}\right) d\left(x_{n}, p\right)+\beta_{n} d\left(v_{n}, p\right)
\end{aligned}
$$




$$
\begin{aligned}
& \leq\left(1-\beta_{n}\right) d\left(x_{n}, p\right)+\beta_{n} H\left(S_{S_{2}} x_{n}, S_{S_{2}} p\right)+\beta_{n} \tau_{n} \\
& \leq\left(1-\beta_{n}\right) d\left(x_{n}, p\right)+\beta_{n}\left\|x_{n}-p\right\|+\beta_{n} \tau_{n} \\
& =\left(1-\beta_{n}\right) d\left(x_{n}, p\right)+\beta_{n} d\left(x_{n}, p\right)+\beta_{n} \tau_{n} \\
& =d\left(x_{n}, p\right)+\beta_{n} \tau_{n} .
\end{aligned}
$$

Substituting (2.3) into (2.2) and simplifying it, we have

$$
d\left(x_{n+1}, p\right) \leq d\left(x_{n}, p\right)+\left(1+\beta_{n}\right) \alpha_{n} \tau_{n},
$$

where $\delta_{n}=0, b_{n}=\left(1+\beta_{n}\right) \alpha_{n} \tau_{n}$. Since $\sum_{n=1}^{\infty} \tau_{n}<\infty$ and condition (2), it follows from Lemma 1.2 that $\lim _{n \rightarrow \infty} d\left(x_{n}, p\right)$ exist for $p \in \mathcal{F}$.

Step 2. We show that

$$
\lim _{n \rightarrow \infty} d\left(x_{n}, T_{T_{i}} x_{n}\right)=0, \quad \lim _{n \rightarrow \infty} d\left(x_{n}, S_{S_{i}} x_{n}\right)=0, \quad i=1,2 .
$$

For each $p \in \mathcal{F}$, from the proof of Step 1, we know that $\lim _{n \rightarrow \infty} d\left(x_{n}, p\right)$ exists. We may assume that $\lim _{n \rightarrow \infty} d\left(x_{n}, p\right)=c \geq 0$. If $c=0$, then the conclusion is trivial. Next, we deal with the case $c>0$. From (2.3), we have

$$
d\left(y_{n}, p\right) \leq d\left(x_{n}, p\right)+\beta_{n} \tau_{n}
$$

Taking lim sup on both sides in (2.6), we have

$$
\limsup _{n \rightarrow \infty} d\left(y_{n}, p\right) \leq c
$$

In addition, since

$$
d\left(T_{T_{1}} y_{n}, p\right)=d\left(T_{T_{1}} y_{n}, T_{T_{1}} p\right) \leq d\left(y_{n}, p\right)
$$

and

$$
d\left(S_{S_{1}} x_{n}, p\right)=d\left(S_{S_{1}} x_{n}, S_{S_{1}} p\right) \leq d\left(x_{n}, p\right)
$$

we have

$$
\limsup _{n \rightarrow \infty} d\left(T_{T_{1}} y_{n}, p\right) \leq c
$$

and

$$
\limsup _{n \rightarrow \infty} d\left(S_{S_{1}} x_{n}, p\right) \leq c
$$

Since $\lim _{n \rightarrow \infty} d\left(x_{n+1}, p\right)=c$, it is easy prove that

$$
\lim _{n \rightarrow \infty} d\left(W\left(S_{S_{1}} x_{n}, T_{T_{1}} y_{n}, \alpha_{n}\right), p\right)=c .
$$


It follows from (2.8)-(2.10) and Lemma 1.3 that

$$
\lim _{n \rightarrow \infty} d\left(S_{S_{1}} x_{n}, T_{T_{1}} y_{n}\right)=0 .
$$

By the same method, we can also prove that

$$
\lim _{n \rightarrow \infty} d\left(S_{S_{2}} x_{n}, T_{T_{2}} x_{n}\right)=0 .
$$

By virtue of the condition (4), it follows from (2.11) and (2.12) that

$$
\lim _{n \rightarrow \infty} d\left(x_{n}, T_{T_{1}} y_{n}\right) \leq \lim _{n \rightarrow \infty} d\left(S_{S_{1}} x_{n}, T_{T_{1}} y_{n}\right)=0
$$

and

$$
\lim _{n \rightarrow \infty} d\left(x_{n}, T_{T_{2}} x_{n}\right) \leq \lim _{n \rightarrow \infty} d\left(S_{S_{2}} x_{n}, T_{T_{2}} x_{n}\right)=0 .
$$

From (2.1) and (2.12) we have

$$
\begin{aligned}
d\left(y_{n}, S_{S_{2}} x_{n}\right) & =d\left(W\left(S_{S_{2}} x_{n}, T_{T_{2}} x_{n}, \beta_{n}\right), S_{S_{2}} x_{n}\right) \\
& \leq \beta_{n} d\left(T_{T_{2}} x_{n}, S_{S_{2}} x_{n}\right) \rightarrow 0 \quad(\text { as } n \rightarrow \infty)
\end{aligned}
$$

and

$$
\begin{aligned}
d\left(y_{n}, S_{S_{1}} x_{n}\right) & =d\left(W\left(S_{S_{1}} x_{n}, T_{T_{1}} x_{n}, \beta_{n}\right), S_{S_{1}} x_{n}\right) \\
& \leq \beta_{n} d\left(T_{T_{1}} x_{n}, S_{S_{1}} x_{n}\right) \rightarrow 0 \quad(\text { as } n \rightarrow \infty) .
\end{aligned}
$$

Observe that

$$
d\left(x_{n}, y_{n}\right)=d\left(x_{n}, T_{T_{2}} x_{n}\right)+d\left(T_{T_{2}} x_{n}, S_{S_{2}} x_{n}\right)+d\left(S_{S_{2}} x_{n}, y_{n}\right) .
$$

It follows from (2.14) and (2.15) that

$$
\lim _{n \rightarrow \infty} d\left(x_{n}, y_{n}\right)=0
$$

This together with (2.13) implies that

$$
\begin{aligned}
d\left(x_{n}, T_{T_{1}} x_{n}\right) & \leq d\left(x_{n}, T_{T_{1}} y_{n}\right)+d\left(T_{T_{1}} y_{n}, T_{T_{1}} x_{n}\right) \\
& \leq d\left(x_{n}, T_{T_{1}} y_{n}\right)+d\left(y_{n}, x_{n}\right) \rightarrow 0 \quad(n \rightarrow \infty) .
\end{aligned}
$$

On the other hand, from (2.11) and (2.17), we have

$$
\begin{aligned}
d\left(S_{S_{1}} x_{n}, T_{T_{1}} x_{n}\right) & \leq d\left(S_{S_{1}} x_{n}, T_{T_{1}} y_{n}\right)+d\left(T_{T_{1}} y_{n}, T_{T_{1}} x_{n}\right) \\
& \leq d\left(S_{S_{1}} x_{n}, T_{T_{1}} y_{n}\right)+d\left(y_{n}, x_{n}\right) \rightarrow 0 \quad(n \rightarrow \infty) .
\end{aligned}
$$


Hence from (2.18) and (2.19), we have

$$
d\left(S_{S_{1}} x_{n}, x_{n}\right) \leq d\left(S_{S_{1}} x_{n}, T_{T_{1}} x_{n}\right)+d\left(T_{T_{1}} x_{n}, x_{n}\right) \rightarrow 0 \quad(n \rightarrow \infty) .
$$

In addition, since

$$
\begin{aligned}
d\left(x_{n+1}, x_{n}\right) & =d\left(W\left(S_{S_{1}} x_{n}, T_{T_{1}} y_{n}, \alpha_{n}\right), x_{n}\right) \\
& \leq\left(1-\alpha_{n}\right) d\left(S_{S_{1}} x_{n}, x_{n}\right)+\alpha_{n} d\left(T_{T_{1}} y_{n}, x_{n}\right),
\end{aligned}
$$

from (2.13) and (2.20), we get

$$
\lim _{n \rightarrow \infty} d\left(x_{n+1}, x_{n}\right)=0 .
$$

Finally, for all $i=1,2$, we have

$$
\begin{aligned}
d\left(x_{n}, T_{T_{i}} x_{n}\right) \leq & d\left(x_{n}, y_{n}\right)+d\left(y_{n}, S_{S_{i}} x_{n}\right) \\
& +d\left(S_{S_{i}} x_{n}, T_{T_{i}} y_{n}\right)+d\left(T_{T_{i}} y_{n}, T_{T_{i}} x_{n}\right) \\
\leq & 2 d\left(x_{n}, y_{n}\right)+d\left(y_{n}, S_{S_{i}} x_{n}\right)+d\left(S_{S_{i}} x_{n}, T_{T_{i}} y_{n}\right),
\end{aligned}
$$

it follows from (2.11), (2.12), (2.15), (2.16), and (2.17) that

$$
\lim _{n \rightarrow \infty} d\left(x_{n}, T_{T_{i}} x_{n}\right)=0, \quad i=1,2 .
$$

Since

$$
d\left(x_{n}, S_{S_{i}} x_{n}\right) \leq d\left(x_{n}, T_{T_{i}} x_{n}\right)+d\left(T_{T_{i}} x_{n}, S_{S_{i}} x_{n}\right),
$$

it follows from (2.12), (2.19), and (2.22) that

$$
\lim _{n \rightarrow \infty} d\left(x_{n}, S_{S_{i}} x_{n}\right)=0, \quad i=1,2 .
$$

Step 3. Now we prove that the sequence $\left\{x_{n}\right\} \Delta$-converges to a common fixed point of $\mathcal{F}:=\bigcap_{i=1}^{2} F\left(T_{T_{i}}\right) \cap F\left(S_{S_{i}}\right)$.

In fact, since for each $p \in F, \lim _{n \rightarrow \infty} d\left(x_{n}, p\right)$ exist. This implies that the sequence $\left\{d\left(x_{n}, p\right)\right\}$ is bounded, and so is the sequence $\left\{x_{n}\right\}$. Hence by virtue of Lemma 1.3, $\left\{x_{n}\right\}$ has a unique asymptotic center $A_{k}\left(\left\{x_{n}\right\}\right)=\left\{x_{n}\right\}$.

Let $\left\{u_{n}\right\}$ be any subsequence of $\left\{x_{n}\right\}$ with $A_{K}\left(\left\{u_{n}\right\}\right)=\{u\}$. It follows from (2.5) that

$$
\lim _{n \rightarrow \infty} d\left(u_{n}, T_{T_{i}} u_{n}\right)=0
$$

Now, we show that $u \in F\left(T_{T_{i}}\right)$. For this, we define a sequence $\left\{z_{n}\right\}$ in $K$ by $z_{j}=T_{T_{i}}^{j} u$. So we calculate

$$
\begin{aligned}
d\left(z_{j}, u_{n}\right) & \leq d\left(T_{T_{i}}^{j} u, T_{T_{i}}^{j} u_{n}\right)+d\left(T_{T_{i}}^{j} u_{n}, T_{T_{i}}^{j-1} u_{n}\right)+\cdots+d\left(T_{T_{i}} u_{n}, u_{n}\right) \\
& =d\left(T_{T_{i}}^{j} u, T_{T_{i}}^{j} u_{n}\right)+\sum_{k=1}^{j} d\left(T_{T_{i}}^{k} u_{n}, T_{T_{i}}^{k-1} u_{n}\right) .
\end{aligned}
$$


Since $T_{T_{i}}$ is a nonexpansive mapping, by $d\left(T_{T_{i}}^{j} u, T_{T_{i}}^{j} u_{n}\right) \leq d\left(T_{T_{i}}^{j-1} u, T_{T_{i}}^{j-1} u_{n}\right) \leq \cdots \leq$ $d\left(u, u_{n}\right), d\left(T_{T_{i}}^{j} u_{n}, T_{T_{i}}^{j-1} u_{n}\right) \leq d\left(T_{T_{i}}^{j-1} u_{n}, T_{T_{i}}^{j-2} u_{n}\right) \leq \cdots \leq d\left(T_{T_{i}} u_{n}, u_{n}\right)$, from (2.25) we have

$$
d\left(z_{j}, u_{n}\right) \leq d\left(u, u_{n}\right)+j d\left(T_{T_{i}} u_{n}, u_{n}\right) .
$$

Taking lim sup on the sides of the above estimate and using (2.24), we have

$$
r\left(z_{j},\left\{u_{n}\right\}\right)=\limsup _{n \rightarrow \infty} d\left(z_{j}, u_{n}\right) \leq \limsup _{n \rightarrow \infty} d\left(u, u_{n}\right)=r\left(u,\left\{u_{n}\right\}\right) .
$$

And so

$$
\limsup _{j \rightarrow \infty} r\left(z_{j},\left\{u_{n}\right\}\right) \leq r\left(u,\left\{u_{n}\right\}\right)
$$

Since $A_{K}\left(\left\{u_{n}\right\}\right)=\{u\}$, by the definition of asymptotic center $A_{K}\left(\left\{u_{n}\right\}\right)$ of a bounded sequence $\left\{u_{n}\right\}$ with respect to $K \subset X$, we have

$$
r\left(u,\left\{u_{n}\right\}\right) \leq r\left(y,\left\{u_{n}\right\}\right), \quad \forall y \in K .
$$

This implies that

$$
\liminf _{j \rightarrow \infty} r\left(z_{j},\left\{u_{n}\right\}\right) \geq r\left(u,\left\{u_{n}\right\}\right)
$$

Therefore we have

$$
\lim _{j \rightarrow \infty} r\left(z_{j},\left\{u_{n}\right\}\right)=r\left(u,\left\{u_{n}\right\}\right) .
$$

It follows from Lemma 1.4 that $\lim _{j \rightarrow \infty} T_{T_{i}} u=u$. As $T_{T_{i}}$ is uniformly continuous, $T_{T_{1}} u=$ $T_{T_{i}}\left(\lim _{j \rightarrow \infty} T_{T_{i}}^{j} u\right)=\lim _{j \rightarrow \infty} T_{T_{i}}^{j+1} u=u$. That is $u \in F\left(T_{T_{i}}\right)$. Similarly, we also can show that $u \in F\left(S_{S_{i}}\right)$. Hence, $u$ is the common fixed point of $T_{T_{i}}$ and $S_{S_{i}}$. Reasoning as above, by utilizing the uniqueness of asymptotic centers, we get $x=u$. Since $\left\{u_{n}\right\}$ is an arbitrary subsequence of $\left\{x_{n}\right\}$, we have $A\left\{u_{n}\right\}=\{u\}$ for all subsequences $\left\{u_{n}\right\}$ of $\left\{x_{n}\right\}$. This proves that $\left\{x_{n}\right\} \Delta$-converges to a common fixed point of $\mathcal{F}:=\bigcap_{i=1}^{2} F\left(T_{T_{i}}\right) \cap F\left(S_{S_{i}}\right)$. This completes the proof.

The following theorem can be obtained from Theorem 2.1 immediately.

Theorem 2.2 Let $K$ be a nonempty closed convex subset of a complete uniformly convex hyperbolic space $X$ with monotone modulus of uniform convexity $\eta$. Let $T_{i}: K \rightarrow P(K), i=$ 1,2 be a multivalued mapping and $T_{T_{i}}$ be a nonexpansive mapping, let $S_{i}: K \rightarrow K, i=1,2$ be a nonexpansive mapping. Assume that $\mathcal{F}:=\bigcap_{i=1}^{2} F\left(T_{T_{i}}\right) \cap F\left(S_{i}\right) \neq \emptyset$, and for arbitrarily chosen $x_{1} \in K,\left\{x_{n}\right\}$ is defined as follows:

$$
x_{n+1}=W\left(S_{1} x_{n}, T_{T_{1}} u_{n}, \alpha_{n}\right), \quad y_{n}=W\left(S_{2} x_{n}, T_{T_{2}} v_{n}, \beta_{n}\right), \quad \forall n \geq 1,
$$

where $v_{n} \in S_{2} x_{n}, u_{n} \in S_{1} y_{n}, d\left(v_{n}, u_{n}\right) \leq H\left(S_{2} x_{n}, S_{1} y_{n}\right)+\tau_{n},\left\{\tau_{n}\right\},\left\{\alpha_{n}\right\}$, and $\left\{\beta_{n}\right\}$ satisfy the following conditions: 
(1) $\lim _{n \rightarrow \infty} \tau_{n}=0, \sum_{n=1}^{\infty} \tau_{n}<\infty$

(2) There exist constants $a, b \in(0,1)$ with $0<b(1-a) \leq \frac{1}{2}$ such that $\left\{\alpha_{n}\right\} \subset[a, b]$ and $\left\{\beta_{n}\right\} \subset[a, b]$.

(3) $\left\|x_{n}-p\right\|=d\left(x_{n}, p\right),\left\|y_{n}-p\right\|=d\left(y_{n}, p\right)$.

(4) $d\left(x, T_{T_{i}} y\right) \leq d\left(S_{i} x, T_{T_{i}} y\right)$, for all $x, y \in K$ and $i=1,2$.

Then the sequence $\left\{x_{n}\right\}$ defined by (2.26) $\Delta$-converges to a common fixed point of $\mathcal{F}:=$ $\bigcap_{i=1}^{2} F\left(T_{T_{i}}\right) \cap F\left(S_{i}\right)$.

Proof Take $S_{S_{i}}=S_{i}$ in Theorem 2.1. Since all conditions in Theorem 2.1 are satisfied, it follows from Theorem 2.1 that the sequence $\left\{x_{n}\right\} \Delta$-converges to a common fixed point of $\mathcal{F}:=\bigcap_{i=1}^{2} F\left(T_{T_{i}}\right) \cap F\left(S_{i}\right)$. This completes the proof of Theorem 2.2.

Theorem 2.3 Let $K$ be a nonempty closed convex subset of a complete uniformly convex hyperbolic space $X$ with monotone modulus of uniform convexity $\eta$. Let $T_{i}: K \rightarrow P(K)$, $i=1,2$ be a multivalued mapping and $T_{T_{i}}, i=1,2$ be a nonexpansive mapping. Let $S_{i}$ : $K \rightarrow P(K), i=1,2$ be a multivalued mapping and $S_{S_{i}}$ be a nonexpansive mapping. Assume that $\mathcal{F}:=\bigcap_{i=1}^{2} F\left(T_{T_{i}}\right) \cap F\left(S_{S_{i}}\right) \neq \emptyset$, for arbitrarily chosen $x_{1} \in K,\left\{x_{n}\right\}$ is defined as follows:

$$
x_{n+1}=W\left(x_{n}, T_{T_{1}} u_{n}, \alpha_{n}\right), \quad y_{n}=W\left(x_{n}, T_{T_{2}} v_{n}, \beta_{n}\right), \quad \forall n \geq 1,
$$

where $v_{n} \in S_{S_{2}} x_{n}, u_{n} \in S_{S_{1}} y_{n}, d\left(v_{n}, u_{n}\right) \leq H\left(S_{S_{2}} x_{n}, S_{S_{1}} y_{n}\right)+\tau_{n}$, I is the identity mapping, $\left\{\tau_{n}\right\}$, $\left\{\alpha_{n}\right\}$, and $\left\{\beta_{n}\right\}$ satisfy the following conditions:

(1) $\lim _{n \rightarrow \infty} \tau_{n}=0, \sum_{n=1}^{\infty} \tau_{n}<\infty$.

(2) There exist constants $a, b \in(0,1)$ with $0<b(1-a) \leq \frac{1}{2}$ such that $\left\{\alpha_{n}\right\} \subset[a, b]$ and $\left\{\beta_{n}\right\} \subset[a, b]$.

(3) $\left\|x_{n}-p\right\|=d\left(x_{n}, p\right),\left\|y_{n}-p\right\|=d\left(y_{n}, p\right)$.

Then the sequence $\left\{x_{n}\right\}$ defined by (2.27) $\Delta$-converges to a common fixed point of $\mathcal{F}:=$ $\bigcap_{i=1}^{2} F\left(T_{T_{i}}\right)$.

Proof Take $S_{S_{i}}=I, i=1,2$ in (2.1). Since all conditions in Theorem 2.1 are satisfied, it follows from Theorem 2.1 that the sequence $\left\{x_{n}\right\} \Delta$-converges to a common fixed point of $\mathcal{F}:=\bigcap_{i=1}^{2} F\left(T_{T_{i}}\right) \cap F\left(S_{S_{i}}\right)$. This completes the proof of Theorem 2.3.

Theorem 2.4 Let $K$ be a nonempty closed convex subset of a complete uniformly convex hyperbolic space $X$ with monotone modulus of uniform convexity $\eta$. Let $S_{i}: K \rightarrow P(K)$, $i=1,2$ be a multivalued mapping and $S_{S_{i}}$ be a nonexpansive mapping. Assume that $\mathcal{F}:=$ $\bigcap_{i=1}^{2} F\left(S_{S_{i}}\right) \neq \emptyset$, and for arbitrarily chosen $x_{1} \in K,\left\{x_{n}\right\}$ is defined as follows:

$$
x_{n+1}=W\left(S_{S_{1}} x_{n}, u_{n}, \alpha_{n}\right), \quad y_{n}=W\left(S_{S_{2}} x_{n}, v_{n}, \beta_{n}\right), \quad \forall n \geq 1,
$$

where $v_{n} \in S_{S_{2}} x_{n}, u_{n} \in S_{S_{1}} y_{n}, d\left(v_{n}, u_{n}\right) \leq H\left(S_{S_{2}} x_{n}, S_{S_{1}} y_{n}\right)+\tau_{n},\left\{\tau_{n}\right\},\left\{\alpha_{n}\right\}$, and $\left\{\beta_{n}\right\}$ satisfy the following conditions:

(1) $\lim _{n \rightarrow \infty} \tau_{n}=0, \sum_{n=1}^{\infty} \tau_{n}<\infty$

(2) There exist constants $a, b \in(0,1)$ with $0<b(1-a) \leq \frac{1}{2}$ such that $\left\{\alpha_{n}\right\} \subset[a, b]$ and $\left\{\beta_{n}\right\} \subset[a, b]$.

(3) $\left\|x_{n}-p\right\|=d\left(x_{n}, p\right),\left\|y_{n}-p\right\|=d\left(y_{n}, p\right)$.

(4) $d(x, y) \leq d\left(S_{S_{i}} x, y\right)$, for all $x, y \in K$ and $i=1,2$. 
Then the sequence $\left\{x_{n}\right\}$ defined by (2.28) $\Delta$-converges to a common fixed point of $\mathcal{F}:=$ $\bigcap_{i=1}^{2} F\left(S_{S_{i}}\right)$.

Proof Take $T_{T_{i}}=I, i=1,2$ in (2.1). Since all conditions in Theorem 2.1 are satisfied, it follows from Theorem 2.1 that the sequence $\left\{x_{n}\right\} \Delta$-converges to a common fixed point of $\mathcal{F}:=\bigcap_{i=1}^{2} F\left(S_{S_{i}}\right)$. This completes the proof of Theorem 2.4.

Theorem 2.5 Let $K$ be a nonempty closed convex subset of a complete uniformly convex hyperbolic space $X$ with monotone modulus of uniform convexity $\eta$. Let $S_{i}: K \rightarrow P(K)$, $i=1,2$ be a multivalued mapping and $S_{S_{i}}$ be a nonexpansive mapping. Assume that $\mathcal{F}:=$ $\bigcap_{i=1}^{2} F\left(S_{S_{i}}\right) \neq \emptyset$, and for arbitrarily chosen $x_{1} \in K,\left\{x_{n}\right\}$ is defined as follows:

$$
x_{n+1}=W\left(x_{n}, u_{n}, \alpha_{n}\right), \quad y_{n}=W\left(x_{n}, v_{n}, \beta_{n}\right), \quad \forall n \geq 1,
$$

where $v_{n} \in S_{S_{2}} x_{n}, u_{n} \in S_{S_{1}} y_{n}, d\left(v_{n}, u_{n}\right) \leq H\left(S_{S_{2}} x_{n}, S_{S_{1}} y_{n}\right)+\tau_{n},\left\{\tau_{n}\right\},\left\{\alpha_{n}\right\}$, and $\left\{\beta_{n}\right\}$ satisfy the following conditions:

(1) $\lim _{n \rightarrow \infty} \tau_{n}=0, \sum_{n=1}^{\infty} \tau_{n}<\infty$.

(2) There exist constants $a, b \in(0,1)$ with $0<b(1-a) \leq \frac{1}{2}$ such that $\left\{\alpha_{n}\right\} \subset[a, b]$ and $\left\{\beta_{n}\right\} \subset[a, b]$.

(3) $\left\|x_{n}-p\right\|=d\left(x_{n}, p\right),\left\|y_{n}-p\right\|=d\left(y_{n}, p\right)$.

(4) $d(x, y) \leq d\left(S_{S_{i}} x, y\right)$, for all $x, y \in K$ and $i=1,2$.

Then the sequence $\left\{x_{n}\right\}$ defined by (2.29) $\Delta$-converges to a common fixed point of $\mathcal{F}:=$ $\bigcap_{i=1}^{2} F\left(S_{S_{i}}\right)$.

Proof Take $S_{S_{i}}=I, i=1,2$ in (2.28). Since all conditions in Theorem 2.4 are satisfied, it follows from Theorem 2.4 that the sequence $\left\{x_{n}\right\} \Delta$-converges to a common fixed point of $\mathcal{F}:=\bigcap_{i=1}^{2} F\left(S_{S_{i}}\right)$. This completes the proof of Theorem 2.5.

Theorem 2.6 Let $K$ be a nonempty closed convex subset of a complete uniformly convex hyperbolic space $X$ with monotone modulus of uniform convexity $\eta$. Let $T_{i}: K \rightarrow K, i=1,2$ be a nonexpansive mapping, let $S_{i}: K \rightarrow P(K), i=1,2$ be a multivalued mapping and $S_{S_{i}}$ be a nonexpansive mapping. Assume that $\mathcal{F}:=\bigcap_{i=1}^{2} F\left(T_{i}\right) \cap F\left(S_{S_{i}}\right) \neq \emptyset$, and for arbitrarily chosen $x_{1} \in K,\left\{x_{n}\right\}$ is defined as follows:

$$
x_{n+1}=W\left(S_{S_{1}} x_{n}, T_{1} u_{n}, \alpha_{n}\right), \quad y_{n}=W\left(S_{S_{2}} x_{n}, T_{2} v_{n}, \beta_{n}\right), \quad \forall n \geq 1,
$$

where $v_{n} \in S_{S_{2}} x_{n}, u_{n} \in S_{S_{1}} y_{n}, d\left(v_{n}, u_{n}\right) \leq H\left(S_{S_{2}} x_{n}, S_{S_{1}} y_{n}\right)+\tau_{n},\left\{\tau_{n}\right\},\left\{\alpha_{n}\right\}$, and $\left\{\beta_{n}\right\}$ satisfy the following conditions:

(1) $\lim _{n \rightarrow \infty} \tau_{n}=0, \sum_{n=1}^{\infty} \tau_{n}<\infty$.

(2) There exist constants $a, b \in(0,1)$ with $0<b(1-a) \leq \frac{1}{2}$ such that $\left\{\alpha_{n}\right\} \subset[a, b]$ and $\left\{\beta_{n}\right\} \subset[a, b]$.

(3) $\left\|x_{n}-p\right\|=d\left(x_{n}, p\right),\left\|y_{n}-p\right\|=d\left(y_{n}, p\right)$.

(4) $d\left(x, T_{i} y\right) \leq d\left(S_{S_{i}} x, T_{i} y\right)$, for all $x, y \in K$ and $i=1,2$.

Then the sequence $\left\{x_{n}\right\}$ defined by (2.30) $\Delta$-converges to a common fixed point of $\mathcal{F}:=$ $\bigcap_{i=1}^{2} F\left(T_{i}\right) \cap F\left(S_{S_{i}}\right)$. 
Proof Take $T_{T_{i}}=T_{i}, i=1,2$ in (2.1). Since all conditions in Theorem 2.1 are satisfied, it follows from Theorem 2.1 that the sequence $\left\{x_{n}\right\} \Delta$-converges to a common fixed point of $\mathcal{F}:=\bigcap_{i=1}^{2} F\left(T_{i}\right) \cap F\left(S_{S_{i}}\right)$. This completes the proof of Theorem 2.6.

We would like to mention that our key result Theorem 2.1 could be regarded as either an extension or an improvement of the corresponding results in the existing literature given by the authors of $[6-9,11-13,15,16,18,20,21,30]$.

We also like to bring to the readers' attention that by using the Baire approach due to the classical paper of de Blasi and Myjak [31], Reich and Zaslavski recently [19] gave a comprehensive study for the so-called genericity in nonlinear analysis, in particular for the study of genericity for the topics in the approximation of fixed points, existence of fixed points, and the convergence and stability of iterates of nonexpansive set-valued mappings in the sense of Baire category, which are different from the ones we have established in this paper.

\title{
Competing interests \\ The authors declare that they have no competing interests.
}

\section{Authors' contributions}

The authors contributed equally and significantly in this research work. All authors read and approved the final manuscript.

\author{
Author details \\ ${ }^{1}$ Institute of Mathematics, Yibin University, Yibin, Sichuan 644000, China. ${ }^{2}$ School of Mathematics and Statistics, \\ Zhengzhou University, Zhengzhou, Henan 450001, China. ${ }^{3}$ School of Digital Media, Jiangnan University, Wuxi, Jiangsu \\ 214122 , China.
}

\section{Acknowledgements}

We like to thank the editors and anonymous referees for their comments and suggestion leading to the present version of the paper. This work was supported by Scientific Research Fund of Sichuan Provincial Education Department (No. 13ZA0199) and the Natural Science Foundation of Yibin University (No. 2012S79). The corresponding author (the third one) was also supported by the 'Six Talent Peaks Project' of Jiangsu Province (No. DZXX-028).

Received: 17 February 2014 Accepted: 4 June 2014 Published: 18 Jul 2014

\section{References}

1. Markin, JT: Continuous dependence of fixed point sets. Proc. Am. Math. Soc. 38, 545-547 (1973)

2. Nadler, SB: Multivalued mappings. Pac. J. Math. 30(2), 475-488 (1969)

3. Gomiewicz, L: Topological Fixed Point Theory of Multivalued Mappings. Kluwer Academic, Dordrecht (1999)

4. Lim, TC: A fixed point theorem for multivalued nonexpansive mappings in a uniformly convex Banach spaces. Bull. Am. Math. Soc. 80, 1123-1126 (1974)

5. Sastry, KPR, Babu, VR: Convergence of Ishikawa iterates for a multivalued mapping with a fixed point. Czechoslov. Math. J. 55, 817-825 (2005)

6. Panyanak, B: Mann and Ishikawa iterative processes for multivalued mappings in Banach spaces. Comput. Math. Appl. 54, 872-877 (2007)

7. Song, Y, Wang, H: Erratum to 'Mann and Ishikawa iterative processes for multivalued mappings in Banach spaces' [Comput. Math. Appl. 54 (2007) 872-877]. Comput. Math. Appl. 55, 2999-3002 (2008)

8. Jung, JS: Strong convergence theorems for multivalued nonexpansive in Banach spaces. Nonlinear Anal. 66, 2345-2354 (2007)

9. Shahzad, N, Zegeye, $\mathrm{H}$ : On Mann and Ishikawa iteration schemes for multivalued maps in Banach spaces. Nonlinear Anal. 71(3-4), 838-844 (2009)

10. Agarwal, RP, O'Regan, D, Sahu, DR: Iterative construction of fixed points of nearly asymptotically nonexpansive mappings. J. Nonlinear Convex Anal. 8(1), 61-79 (2007)

11. Khan, SH, Kim, JK: Common fixed points of two nonexpansive mappings by a modified faster iteration scheme. Bull. Korean Math. Soc. 47(5), 973-985 (2010)

12. Song, Y, Cho, JY: Some notes on Ishikawa iteration for multivalued mappings. Bull. Korean Math. Soc. 48(3), 575-584 (2011). doi:10.4134/BKMS.2011.48.3.575

13. Khan, SH, Abbas, M, Rhoades, BE: A new one-step iterative scheme for approximating common fixed points of two multivalued nonexpansive mappings. Rend. Circ. Mat. Palermo 59, 149-157 (2010)

14. Khan, SH, Fukhar-ud-din, H: Weak and strong convergence of a scheme with errors for two nonexpansive mappings. Nonlinear Anal. 8, 1295-1301 (2005)

15. Khan, SH, Yildifim, L: Fixed points of multivalued nonexpansive mappings in Banach spaces. Fixed Point Theory Appl. 2012, 73 (2012). doi:10.1186/1687-1812-2012-73 
16. Senter, HF, Dotson, WG: Approximating fixed points of nonexpansive mappings. Proc. Am. Math. Soc. 44(2), 375-380 (1974)

17. Assad, NA, Kirk, WA: Fixed point theorems for set-valued mappings of contractive type. Pac. J. Math. 43, 553-562 (1972)

18. Reich, S: Fixed points of contractive functions. Boll. Unione Mat. Ital. 5(4), 26-42 (1972)

19. Reich, S, Zaslavski, AJ: Set-valued mappings. In: Genericity in Nonlinear Analysis, pp. 449-480. Springer, Berlin (2014)

20. Goebel, K, Reich, S: Uniform Convexity, Hyperbolic Geometry and Nonexpansive Mappings. Dekker, New York (1984)

21. Reich, S, Shafrir, I: Nonexpansive iterations in hyperbolic spaces. Nonlinear Anal. 15, 537-558 (1990)

22. Kohlenbach, U: Some logical metatheorems with applications in functional analysis. Trans. Am. Math. Soc. 357(1), 89-128 (2004)

23. Kuhfittig, PKF: Common fixed points of nonexpansive mappings by iteration. Pac. J. Math. 97(1), 137-139 (1987)

24. Sahin, A, Basarir, M: On the strong convergence of a modified S-iteration process for asymptotically quasi-nonexpansive mappings in a CAT(0) space. Fixed Point Theory Appl. 2013, 12 (2013). doi:10.1186/1687-1812-2013-12

25. Bridson, N, Haefliger, A: Metric Spaces of Non-Positive Curvature. Springer, Berlin (1999)

26. Leustean, L: A quadratic rate of asymptotic regularity for CAT(0) spaces. J. Math. Anal. Appl. 235, 386-399 (2007)

27. Leustean, L: Nonexpansive iteration in uniformly convex W-hyperbolic spaces. In: Leizarowitz, A, Mordukhovich, BS, Shafrir, I, Zaslavski, A (eds.) Nonlinear Analysis and Optimization I: Nonlinear Analysis. Contemporary Mathematics, vol. 513, pp. 193-209. Am. Math. Soc., Providence (2010)

28. Chang, SS, Wang, L, Lee, HWJ, Chan, CK: Total asymptotically nonexpansive mappings in a CAT(0) space demiclosed principle and $\Delta$-convergence theorems for total asymptotically nonexpansive mappings in a CAT(0) space. Appl. Math. Comput. 219, 2611-2617 (2012)

29. Khan, AR, Fukhar-ud-din, H, Kuan, MAA: An implicit algorithm for two finite families of nonexpansive maps in hyperbolic spaces. Fixed Point Theory Appl. 2012, 54 (2012). doi:10.1186/1687-1812-2012-54

30. Zhao, LC, Chang, SS, Kim, JK: Mixed type iteration for total asymptotically nonexpansive mappings in hyperbolic spaces. Fixed Point Theory Appl. 2013, 353 (2013). doi:10.1186/1687-1812-2013-353

31. de Blasi, FS, Myjak, J: Sur la convergence des approximations successives pour les contractions non linéaires dans un espace de Banach. C. R. Acad. Sci. Paris, Ser. A-B 283, 185-187 (1976) (French)

10.1186/1687-1812-2014-140

Cite this article as: Lei et al.: Mixed type iterations for multivalued nonexpansive mappings in hyperbolic spaces. Fixed Point Theory and Applications 2014, 2014:140

\section{Submit your manuscript to a SpringerOpen ${ }^{\circ}$ journal and benefit from:}

- Convenient online submission

- Rigorous peer review

- Immediate publication on acceptance

- Open access: articles freely available online

- High visibility within the field

- Retaining the copyright to your article 